\title{
Nitretação por plasma com revenimento simultâneo do aço ferramenta VF 800AT
}

\author{
Plasma nitriding and simultaneous tempering \\ of VF 800AT tool steel
}

André Ricardo Prass ${ }^{1}$, Luis Cesar Fontana ${ }^{1}$, Abel André Cândido Recco ${ }^{1}$

\author{
${ }^{1}$ Universidade do Estado de Santa Catarina - UDESC -Rua Paulo Malschitzki, 200, CEP 89219-710 Joinville, Brasil \\ e-mail: prass.andrericardo@gmail.com \\ e-mail: luis.fontana@udesc.br; abel.recco@udesc.br
}

\section{RESUMO}

A nitretação por plasma é um tratamento termoquímico que modifica as propriedades superficiais de um determinado material. Este processo aplicado em aços ferramenta resulta no aumento da dureza da superfície através da formação da zona de difusão pelo controle das variáveis de tratamento, tais como a temperatura, composição química da atmosfera de trabalho e tempo de tratamento. Neste trabalho discute-se um procedimento alternativo para o tratamento térmico de revenimento. O qual possibilita a redução nos custos de fabricação, diminuição no consumo de energia e no tempo de confecção das ferramentas. Amostras de aço ferramenta VF 800 AT foram temperadas e revenidas (três vezes) pelo tratamento térmico convencional com posterior nitretação por plasma. Em cinco outros grupos de amostras realizou-se o revenimento concomitantemente ao tratamento de nitretação. A superfície e o núcleo das amostras foram caracterizados por difração de raios x, microscopia ótica, microscopia eletrônica de varredura, microdureza Vickers e dureza Rockwell C. Os resultados mostram que o gradiente térmico entre a superfície e o núcleo das amostras afeta a microestrutura, a dureza e as fases obtidas durante o tratamento térmico de revenimento simultâneo à nitretação. Entretanto, quando dois revenimentos são realizados em forno tipo Mufla e o último tratamento ocorre simultaneamente à nitretação, obtêm-se microestruturas, fases, dureza e microdureza semelhantes ao ciclo de tratamento térmico convencional com posterior nitretação por plasma.

Palavras -chave: Aço ferramenta, nitretação por plasma, revenimento.

\begin{abstract}
Plasma nitriding of tool steels improves the surface hardness due to formation of diffusion zone and/or compound layer. The process parameters such as temperature, gas composition and dwell time, allow us to control the layer thickness, the microstructure, the crystalline phases and the type of layer (for example white layer or diffusion zone). This paper discusses an alternative procedure for the heat treatment of tempering and surface treatment, both in plasma or combining conventional heat treatment with subsequent plasma nitriding. Carring out both treatments in plasma could enable reduction in manufacturing costs, lower energy consumption and less time for tools manufacturing. Samples of VF800AT steel were treated and characterized (at surface and core of samples) through the following technique: X-ray diffraction, optical microscopy, scanning electron microscopy, micro-hardness profile and Rockwell $\mathrm{C}$ measurement. Temperature measurements during the plasma treatment, show that arise thermal gradient between the surface and the core of the samples. In this work, it was observed that the surface was up to $7 \%$ hotter than the core of sample, during the plasma treatment with temperature of magnitude about $5 \times 10^{2}{ }^{\circ} \mathrm{C}$. This thermal gradient seems inherent to the plasma process, so that it can produce different microstructure, hardness and crystalline phases between core and edge of samples. However, when two tempering operations are prior carried out in a muffle furnace and the third tempering treatment is subsequently carried out simultaneously with the plasma nitriding, it is observed that the microstructure, the crystalline phases, hardness and micro hardness (in both, edge and core) are similar to treatments done in conventional mode cycle (in muffle furnace) with subsequent plasma nitriding.
\end{abstract}

Keywords: Tool steel, plasma nitriding, tempering. 


\section{INTRODUÇÃO}

$\mathrm{O}$ aço ferramenta para trabalho a frio VF 800 AT é utilizado na indústria metal mecânica para a produção de punções, cavidades, matrizes, ferramentas de corte, conformação, machos e peças estruturais. Em sua aplicação ocorre o contato direto entre a ferramenta e o material processado que geram esforços mecânicos na superfície de contato da ferramenta com a peça fabricada conforme MENDANHA, et al.[1]. As tensões geradas nessas superfícies de contato causam desgaste pelo uso contínuo, deformações, fraturas, trincas que afetam a vida útil da ferramenta e o rendimento.

Os fabricantes de aço ferramenta, de forma geral, comercializam os aços na condição recozida, com matriz ferrítica e com precipitação de carbonetos em sua microestrutura. Os aços são fornecidos com baixa dureza (na faixa de 200 a $320 \mathrm{HB}$ ) para facilitar as etapas de usinagem que visam melhorar a condição de fabricação das ferramentas. Para serem aplicados como ferramentas, estes aços devem ser tratados termicamente em uma seqüência de tratamentos térmicos de pré-aquecimento, austenitização, têmpera, alívio de tensões, subzero, revenimento e tratamento de endurecimento superficial como a nitretação a plasma e/ou recobrimentos com filmes finos. Estes tratamentos são convencionalmente aplicados de maneira isolada e seqüencial na fabricação das ferramentas.

A nitretação forma uma camada dura na superfície da peça, a qual possibilita melhorar a resistência ao desgaste do substrato, a adesão entre o filme e substrato e redução no gradiente de propriedades entre as interfaces, evitando defeitos nas ferramentas durante as operações de corte e repuxo. Além disso, a camada nitretada permite suporte mecânico para revestimentos cerâmicos posteriores. A composição química da mistura dos gases que geram o plasma contém, em geral, $\mathrm{H}_{2}, \mathrm{~N}_{2} \mathrm{e}$ Argônio. Essa mistura de gases na atmosfera de trabalho é útil para adequar as características do plasma, de modo a fornecer nitrogênio atômico em níveis controláveis a fim de evitar a formação de camada composta (camada branca), melhorar a difusão e a espessura da camada endurecida conforme FRANCO JR.[2].

As fases constituintes da microestrutura do aço ferramenta tratadas termicamente são: matriz martensítica revenida, carbonetos primários e secundários e a ausência (ou baixos níveis residuais) de austenita retida. É comum especificar o tratamento térmico por faixa de dureza final da peça, conforme SILVA et al [3]. Porém esse controle não garante o mesmo comportamento do aço ferramenta tratado para mesma faixa de dureza, devido a variações na microestrutura e nas fases presentes causando alteração nos limites de resistência e na tenacidade. A aplicação de tratamentos simultâneos de revenimento e nitretação por plasma foi realizado por LESKOVSSEK, PODGORNIK [4] no aço ferramenta S390 MC. Os autores discutem o uso de tecnologia de fornos de nitretação por plasma para tratamento térmico de revenimento e nitretação realizados simultaneamente em aço ferramenta. Isso possibilita a redução nos custos de fabricação, diminuição no consumo de energia e no tempo de confecção das ferramentas. O presente trabalho tem o objetivo de estudar a influência do tratamento térmico de revenimento e nitretação por plasma realizados concomitantemente e seus efeitos nas fases cristalinas, microdureza e na microestrutura do núcleo e da superfície das amostras tratadas termicamente.

\section{MATERIAIS E MÉTODOS}

\subsection{Composição química Material}

O material utilizado neste trabalho foi o aço ferramenta para trabalho a frio VF800AT® fabricado pela empresa Villares Metals. O aço é fornecido na condição recozida com dureza de $250 \mathrm{HB}$, na forma de barras cilíndricas com diâmetro de $25,4 \mathrm{~mm}$. A composição química do material é apresentada na Tabela 1 e foi obtida pela técnica de espectroscopia de emissão óptica - SHIMADZU modelo OES-5500 II. A composição química mostrada na Tabela 1 corresponde ao valor médio de três medidas de composição química realizada no material como recebido. 
Tabela 1: Composição química (porcentagem em peso) do aço ferramenta para trabalho a frio VF 800.

\begin{tabular}{l|c}
\hline ELEMENTO & MEDIDO \\
\hline $\mathrm{C}$ & $0,89 \pm 0,01$ \\
\hline $\mathrm{Si}$ & $0,98 \pm 0,02$ \\
\hline $\mathrm{Mn}$ & $0,38 \pm 0,01$ \\
\hline $\mathrm{Cr}$ & $9,06 \pm 0,07$ \\
\hline $\mathrm{Mo}$ & $2,77 \pm 0,02$ \\
\hline $\mathrm{V}$ & $0,452 \pm 0,01$ \\
\hline $\mathrm{Ni}$ & $0,237 \pm 0,001$ \\
\hline $\mathrm{W}$ & $0,329 \pm 0,005$ \\
\hline $\mathrm{Fe}$ & balanço \\
\hline
\end{tabular}

\subsection{Corpos de prova}

Os corpos de prova foram obtidos a partir de uma barra cilíndrica recozida, usinados no formato de cilindro com dimensões de 25,4 $\mathrm{mm}$ de diâmetro e 25,4 mm de comprimento e com retirada dos cantos vivos. Em cada amostra foi usinado rosca M4 para fixação dos corpos de prova ao porta amostras no reator de nitretação conforme representado na Figura 1-a. Para cada grupo de amostras foram preparados oito corpos de prova (Figura 1-b). Em uma amostra foram alojados dois termopares do tipo K dispostos conforme mostra a Figura 1-a. O objetivo de usar dois termopares foi para determinar a diferença de temperatura entre a superfície e o núcleo da amostra durante o tratamento térmico de revenimento simultâneo a nitretação.

a)

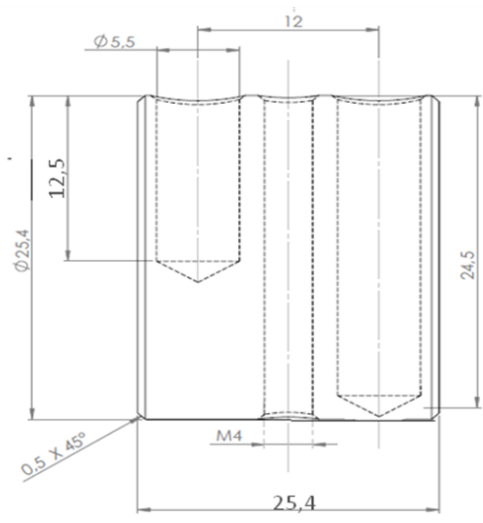

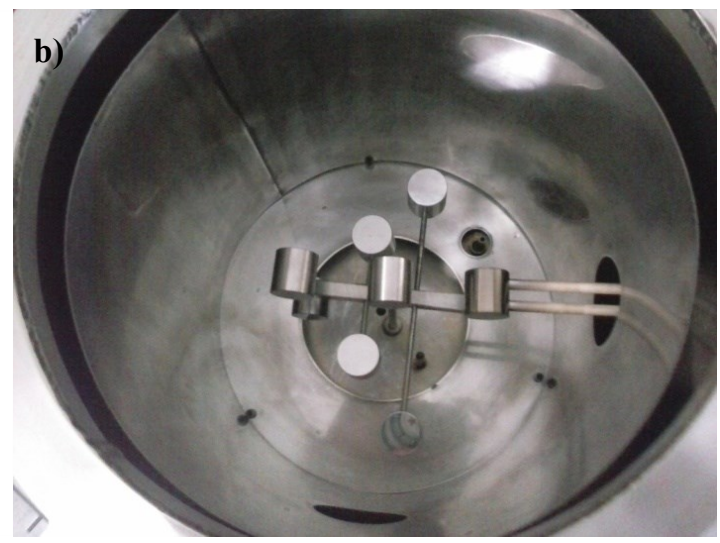

Figura 1: a- Corpo de prova com dimensões de $25,4 \mathrm{~mm}$ por $25,4 \mathrm{~mm}$ de diâmetro contendo dois alojamentos para os termopares e rosca de fixação ao suporte da amostra para montagem no reator. b- Montagem das amostras e dos termopares para monitoramento do gradiente de temperatura entre o núcleo e a superfície da amostra no reator.

\subsection{Tratamento térmico}

Após a usinagem e a preparação das amostras, as mesmas foram tratadas termicamente em diferentes ciclos térmicos formando seis grupos diferentes. A têmpera foi realizada em forno a vácuo, em uma empresa especializada em serviço de tratamento térmico, com aquecimento a $1080{ }^{\circ} \mathrm{C} \pm 3{ }^{\circ} \mathrm{C}$ com patamar de 2 horas seguido de resfriamento em nitrogênio gasoso a uma pressão de 3,5 bar $\left(3,5 \times 10^{5} \mathrm{~Pa}\right)$ até a temperatura de $500^{\circ} \mathrm{C} \pm 3{ }^{\circ} \mathrm{C}$. As amostras foram mantidas nessa condição durante 30 minutos para realização do tratamento térmico de martêmpera. Em seguida foram resfriadas com fluxo de ar até a temperatura de $25{ }^{\circ} \mathrm{C}$. No tratamento térmico de têmpera a diferença de temperatura entre a superfície e núcleo foi de $5{ }^{\circ} \mathrm{C}$.

Os ciclos térmicos realizados em cada um dos 6 grupos de amostras são mostrados na Tabela 2. As amostras do grupo 1 receberam um ciclo de alívio de tensões, o ciclo de tratamento recomendado pelo fabricante, denominado ciclo de alta tenacidade. Esse ciclo consiste em um revenimento a $510{ }^{\circ} \mathrm{C}$, seguido de 2 revenimentos a $540{ }^{\circ} \mathrm{C}$ em forno Mufla. $\mathrm{O}$ tratamento de nitretação por plasma foi realizado na temperatura de $540{ }^{\circ} \mathrm{C}$ posterior ao triplo revenimento realizado no reator a plasma durante duas horas. As amostras do 
grupo 2 receberam o tratamento conforme o ciclo de alta tenacidade recomendado pelo fabricante. As amostras do grupo 3 receberam um ciclo de revenimento a $510{ }^{\circ} \mathrm{C}$, em forno Mufla, e 2 ciclos de revenimento e nitretação simultâneos a $540{ }^{\circ} \mathrm{C}$ no reator a plasma. As amostras do grupo 4 receberam um ciclo de alívio de tensões, um ciclo de revenimento a $510{ }^{\circ} \mathrm{C}$, um ciclo de revenimento a $540{ }^{\circ} \mathrm{C}$, em forno Mufla, e um ciclo de revenimento e nitretação simultâneos a $540{ }^{\circ} \mathrm{C}$ no reator a plasma. No Grupo 5 foram feitos somente três revenimentos em plasma de atmosfera inerte $\left(\mathrm{Ar}+\mathrm{H}_{2}\right)$, isto é, o plasma de gás inerte foi usado como fonte de calor para o tratamento térmico das amostras. Os parâmetros utilizados foram os mesmos dos demais grupos sendo interrompido o fluxo de nitrogênio durante os ciclos de tratamento térmico. Neste grupo de amostras não houve nitretação da superfície. As amostras do grupo 6 receberam um ciclo de revenimento a $510{ }^{\circ} \mathrm{C} \mathrm{em}$ forno Mufla e dois ciclos de revenimento e nitretação simultâneos à $540^{\circ} \mathrm{C}$, no reator a plasma. Em todos os grupos o resfriamento foi feito sob vácuo no interior do reator.

Para o tratamento térmico de alívio de tensões, as amostras foram aquecidas até a temperatura de $180{ }^{\circ} \mathrm{C}$ e mantidas nesta temperatura por 2 horas em fluxo de nitrogênio (para evitar oxidação e contaminações da superfície). Após isso, as amostras foram resfriadas até temperatura ambiente em fluxo de nitrogênio.

Todas as amostras foram submetidas ao tratamento criogênico com imersão em nitrogênio líquido durante 120 minutos.

Tabela 2: Resumo dos ciclos térmicos aplicados aos6 grupos de amostras usados neste trabalho.

\begin{tabular}{|c|c|c|c|c|c|c|c|c|}
\hline AMOSTRA & $\begin{array}{c}\text { ALÍVIO } \\
\text { DE } \\
\text { TENSÕES }\end{array}$ & $\begin{array}{l}1^{\circ}-\text { REV. } \\
\text { MUFLA }\end{array}$ & $\begin{array}{l}2^{\circ} \text { REV. } \\
\text { MUFLA }\end{array}$ & $\begin{array}{l}3^{\circ} \text { REV. } \\
\text { MUFLA }\end{array}$ & $\begin{array}{l}\text { 1- REV. } \\
\text { PLASMA }\end{array}$ & $\begin{array}{l}2^{\circ}-\text { REV. } \\
\text { PLASMA }\end{array}$ & $\begin{array}{c}3^{\circ} \text { REV } \\
\text { PLASMA }\end{array}$ & $\begin{array}{c}\text { TEMPO DE } \\
\text { NITRETAÇÃO } \\
\text { POR } \\
\text { PLASMA }\end{array}$ \\
\hline Grupo 1 & Sim & $510^{\circ} \mathrm{C}$ & $540^{\circ} \mathrm{C}$ & $540^{\circ} \mathrm{C}$ & & & & $2,0 \mathrm{H}$ \\
\hline Grupo 2 & Não & $510^{\circ} \mathrm{C}$ & $540^{\circ} \mathrm{C}$ & $540{ }^{\circ} \mathrm{C}$ & & & & $\mathrm{OH}$ \\
\hline Grupo 3 & Sim & $510^{\circ} \mathrm{C}$ & & & & $540^{\circ} \mathrm{C}$ & $540^{\circ} \mathrm{C}$ & $4,0 \mathrm{H}$ \\
\hline Grupo 4 & Sim & $510^{\circ} \mathrm{C}$ & $540^{\circ} \mathrm{C}$ & & & & $540^{\circ} \mathrm{C}$ & $2,0 \mathrm{H}$ \\
\hline \begin{tabular}{|l|} 
Grupo 5 \\
\end{tabular} & Sim & & & & $510^{\circ} \mathrm{C}$ & $540^{\circ} \mathrm{C}$ & $540^{\circ} \mathrm{C}$ & $\mathrm{OH}$ \\
\hline Grupo 6 & Não & $510^{\circ} \mathrm{C}$ & & & & $540^{\circ} \mathrm{C}$ & $540^{\circ} \mathrm{C}$ & $4,0 \mathrm{H}$ \\
\hline
\end{tabular}

\subsection{Tratamento simultâneo de nitretação por plasma e revenimento}

A nitretação por plasma foi realizada no reator do laboratório de Plasma (Lab - Plasma) da Universidade do Estado de Santa Catarina - Udesc de Joinville - SC. A Figura 2 mostra a representação esquemática do equipamento.

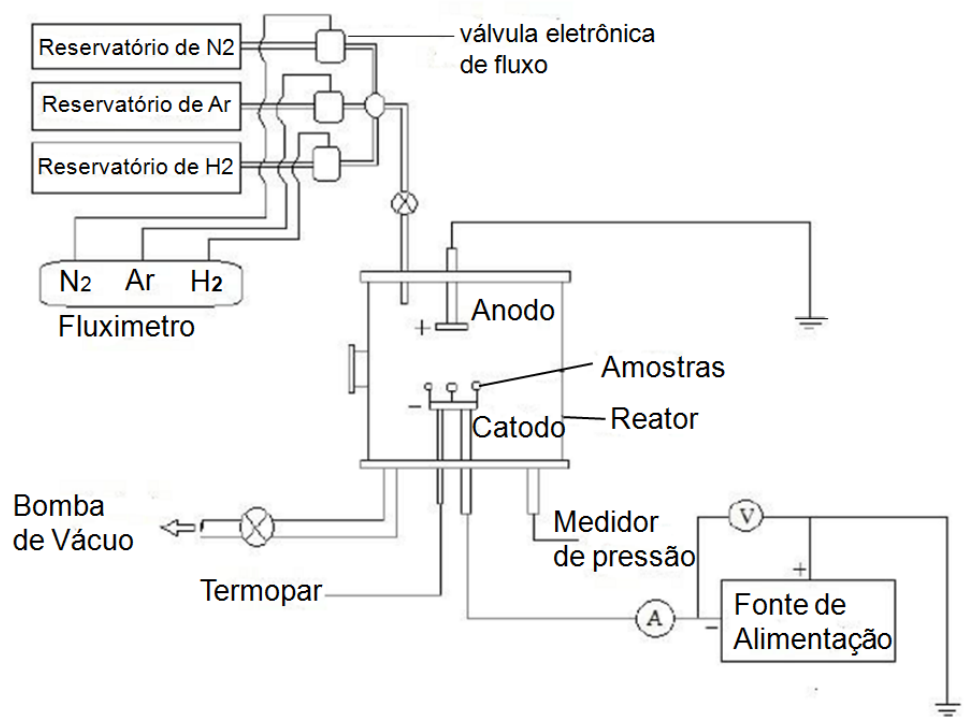

Figura 2: Esquema do reator experimental de parede fria utilizado para o tratamento simultâneo de revenimento e/ou nitretação por plasma. 
O equipamento consiste em um reator (câmera de descarga) feito de aço inoxidável AISI 304 com 300 $\mathrm{mm}$ de diâmetro e $300 \mathrm{~mm}$ de comprimento. No reator do tipo câmera fria, as paredes da câmara não são previamente aquecidas (e mantidas em alta temperatura) para auxiliar na manutenção uniforme da temperatura. O sistema possui uma bomba de vácuo mecânica com capacidade de $18 \mathrm{~m}^{3} / \mathrm{h}$ conectada ao reator, a qual é responsável por produzir vácuo da ordem de $10^{-3}$ Torr; cilindros de gases $\mathrm{H}_{2}, \mathrm{~N}_{2}$ e Ar; fluxo em sccm (standart cubic centimeter per minute); fluxímetro para controle da composição química da mistura gasosa; uma fonte de alimentação de corrente contínua e medidores de pressão e temperatura. As peças foram lavadas com detergente neutro, em seguida foram limpas em álcool sob ultrassom durante 15 minutos, secas com ar quente e posteriormente foram montadas no porta amostras do reator.

A pressão base no reator foi de $3,2 \times 10^{-2}$ Torr. A Tabela 3 mostra as condições de revenimento simultâneo à nitretação, utilizadas neste trabalho. A fonte de tensão contínua (DC) foi utilizada para geração e manutenção do plasma, a qual mantém a descarga na região abnormal. Após o término do tratamento as amostras foram resfriadas até a temperatura ambiente sob vácuo. No triplo revenimento do grupo 5 não se utilizou o $\mathrm{N}_{2}$ durante o tratamento sendo os demais parâmetros iguais aos mostrados na Tabela 3 .

Tabela 3: Descrição dos parâmetros experimentais usados no tratamento de nitretação-revenimento simultâneo.

\begin{tabular}{c|c|c|c|c|c}
\hline Fluxo de $\mathrm{N}_{2}(\mathrm{sccm})$ & Fluxo de $\mathrm{H}_{2}(\mathrm{sccm})$ & Fluxo de $\mathrm{Ar}(\mathrm{sccm})$ & $\mathrm{P}(\mathrm{Torr})$ & $\mathrm{T}\left({ }^{\circ} \mathrm{C}\right)$ & $\mathrm{T}(\mathrm{min})$ \\
\hline 5,5 & 98,0 & 16,0 & 5,0 & 540,0 & 120,0 \\
\hline
\end{tabular}

\subsubsection{Diferença de temperatura entre o núcleo e a superfície das amostras}

$\mathrm{O}$ tratamento de revenimento e nitretação, quando realizado em reator de parede fria, pode apresentar gradiente térmico entre o núcleo e a superfície da amostra. A fonte de calor responsável pelo aquecimento da peça que está sendo tratada é o próprio plasma, o qual é alimentado (em nosso caso) por uma fonte de tensão contínua. Na Figura 2 são mostrados os gráficos da temperatura em função do tempo de tratamento durante o ciclo simultâneo de revenimento e nitretação por plasma. Em cada grupo de tratamento foram tratadas oito amostras concomitantemente e em uma delas foi inserido o termopar como mostra a Figura 1-a.
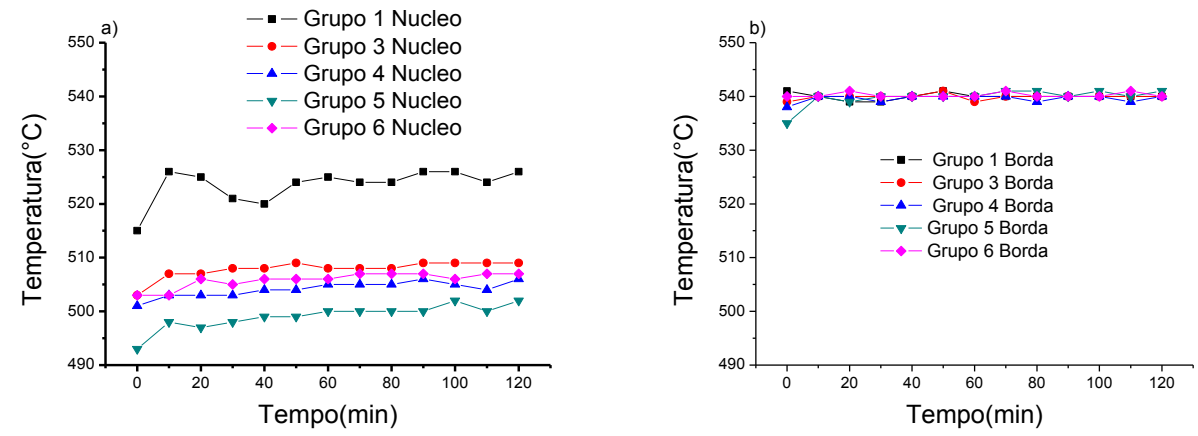

Figura 3: Evolução temporal da temperatura das amostras durante seus respectivos tratamentos: (a) Temperatura no núcleo da amostra e (b) Temperatura próximo à superfície da amostra (0,10 $\mathrm{mm}$ abaixo da superfície).

\subsection{Microscopia Ótica}

Para realizar a análise da microestrutura da camada nitretada a amostra foi seccionada em máquina de corte a frio ISOMET 4000 com disco de diamante, e posteriormente foi embutida em baquelite. Para evitar o abaulamento da extremidade da amostra, durante sua preparação (lixamento e polimento), antes do processo de embutimento, as duas metades cortadas foram coladas com as superfícies tratadas dispostas uma contra a outra. As amostras embutidas foram lixadas com seqüência distintas de granulação de lixas para proporcionar a remoção dos riscos. O polimento foi realizado com abrasivo de alumina $1,0 \mu \mathrm{m}$ de granulação. $\mathrm{O}$ ataque químico utilizado foi nital $4,0 \%$ durante 2,0 minutos. 
Para caracterizações metalográfica da microestrutura do núcleo das amostras, as mesmas foram cortadas segundo o plano que secciona o centro do corpo de provas, em $12,5 \mathrm{~mm}$ da extremidade plana do cilindro. O ataque químico utilizado foi o nital $10,0 \%$ durante 3,0 minutos. A análise por microscopia ótica foi realizada em um microscópio óptico ZEISS Axioskop.

\subsection{Microdureza}

Para medir a microdureza das amostras, foi utilizado um microdurometro marca Shimadzu HMV-2T. O equipamento permite a utilização de cargas previamente especificadas que variam entre $0,294 \mathrm{mN}$ a $16,2 \mathrm{~N}$. Nos perfis de microdureza da camada nitretada utilizou-se a carga de $980,7 \mathrm{mN}$, aplicada durante $10 \mathrm{~s}$. A primeira indentação de cada amostra foi feita a $10 \mu \mathrm{m}$ da superfície e as medidas seguintes foram realizadas a $20 \mu \mathrm{m}, 35 \mu \mathrm{m}, 50 \mu \mathrm{m}, 60 \mu \mathrm{m}, 80 \mu \mathrm{m}, 95 \mu \mathrm{m}, 110 \mu \mathrm{m}, 150 \mu \mathrm{m}$ e $200 \mu \mathrm{m}$. Esse procedimento foi repetido três vezes para cada amostra.

No perfil de microdureza do núcleo utilizou-se uma carga de $9,807 \mathrm{~N}$, aplicada durante $10 \mathrm{~s}$. A primeira indentação foi feita à $1,00 \mathrm{~mm}$ da superfície e as medidas seguintes foram realizadas a cada $1,00 \mathrm{~mm}$ até a profundidade de 10,00 $\mathrm{mm}$. Esse procedimento foi repetido três vezes em cada amostra.

\subsection{Microscopia Eletrônica de Varredura (MEV)}

Para medir a espessura da camada nitretada e analisar a microestrutura das amostras, foi utilizado um microscópio eletrônico de varredura com canhão de efeito de campo (Field EmissionGun- FEG) Jeol JSM-6701F e um Microscópio Eletrônico Phillips XL30. Os microscópios permitem realizar imagens através da deteção de elétrons por diferentes modos como elétrons secundários (secondary electrons image - SEI), elétrons secundários de baixa energia (low energy image -LEI) e detecção por elétrons retroespalhados (backscaterring electrons - BSE).

\subsection{Difração de raios-X}

Para realizar a análise das fases cristalinas presentes na camada nitretada e no núcleo da amostra foi utilizado um difratômetro Shimadzu, com radiação de comprimento de onda 1,5406 $\AA$ (Cobre $\mathrm{K} \alpha$ ). A tensão e a corrente utilizadas foram de $40 \mathrm{kV}$ e $30 \mathrm{~mA}$, respectivamente. A velocidade de varredura utilizada foi de 2 graus por minuto.

\subsection{Dureza Rockwell C do núcleo}

Para realizar caracterização de dureza Rockwell C (HRC) do núcleo foi utilizado durômetro universal de bancada Reicherter, com calibração aferida com padrão de medição. Cinco indentações foram realizadas no núcleo em cada amostra.

\section{RESULTADOSE DISCUSSÕES}

\subsection{Caracterizações da microestrutura do núcleo das amostras.}

\subsubsection{Microscopia óptica.}

Os resultados de microscopia óptica dos diferentes grupos são mostrados na Figura 4. A microestruturas dos grupos 1, 2, 3 e 4 são mostrados nas Figuras 4-a a 4-d. Esses grupos possuem uma microestrutura semelhante, que é formada por uma matriz composta de martensita revenida (confirmada por MEV e microdureza), carbonetos primários $(\mathrm{CP})$ e carbonetos secundários (CS) com distribuição uniforme. Essa microestrutura é típica do aço ferramenta VF 800AT tratado termicamente. Os fatores associados à sua obtenção no tratamento térmico são a velocidade de resfriamento, que possibilitou a transformação da austenita em martensita e o tratamento subzero, que reduz a fração volumétrica da austenita retida conforme FARINA, et al[5], AKHBARIZADEH, et al, [6], CHI HONG-XIAO, et al[7]. 

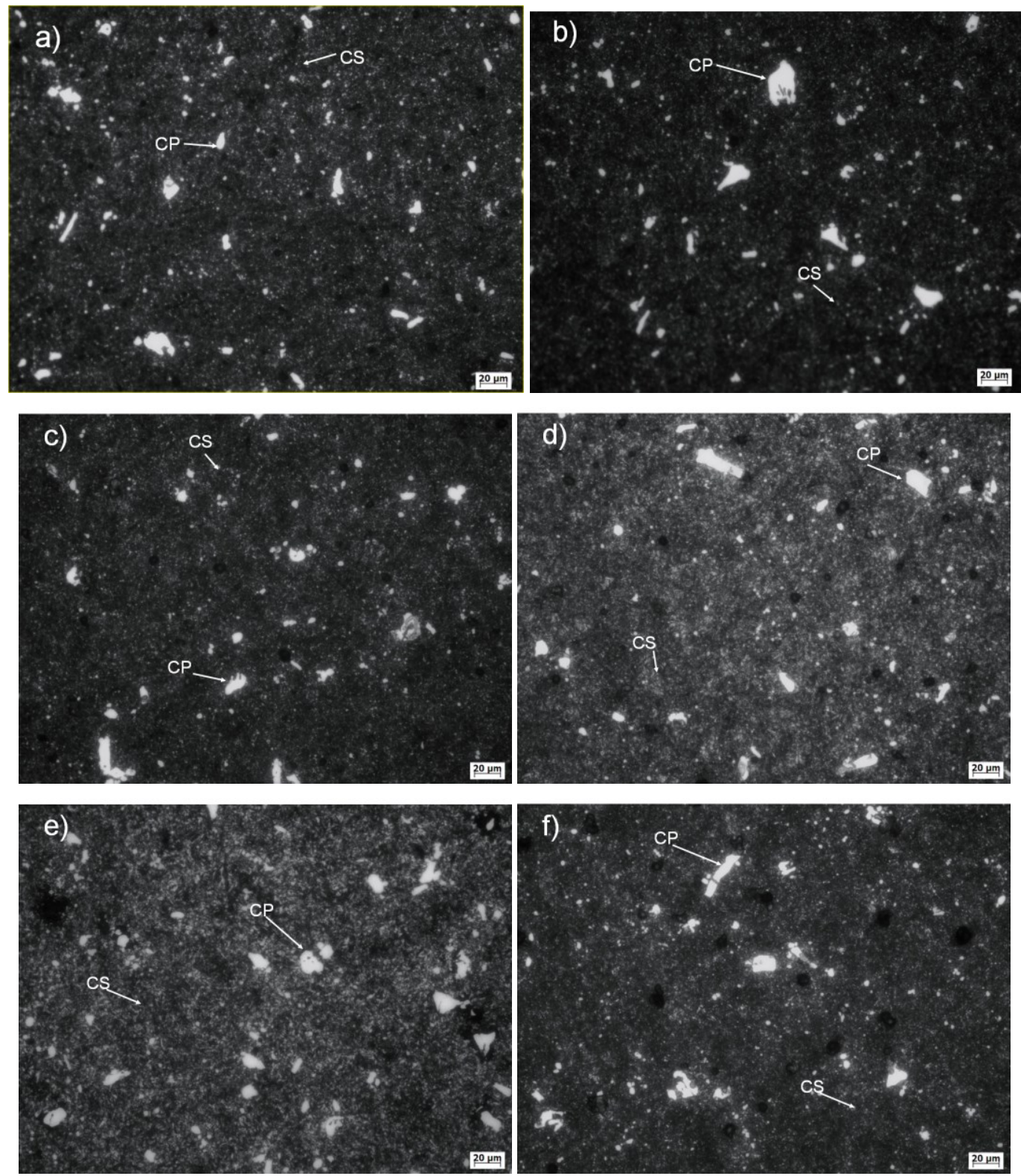

Figura 4: Microestrutura do núcleo: (a) Grupo 1, (b) grupo 2, (c) grupo 3, (d) grupo 4, (e) grupo 5 e (f) grupo 6. Ataque Nital 10\%. Legenda: AR:Austenita retida; CP: Carbonetos primários.; CS: Carbonetos secundários.

Observa-se que a microestrutura dos grupos 3 (Figura 4-c) e 4(Figura4-d) são semelhantes. No grupo 3 foram realizados os tratamentos de alívio de tensões, um ciclo de revenimento em forno Mufla e 2 ciclos simultâneos de nitretação e revenimento por plasma. Para o grupo 4, foi realizado alívio de tensões, 2 ciclos de revenimento em forno Mufla e um ciclo simultâneo de nitretação e revenimento. A microestrutura do grupo 5 mostrada na Figura 4-e, indica uma matriz de martensita que foi confirmado pelos resultados de dureza, pontos claros que são os carbonetos primários $(\mathrm{CP})$, carbonetos secundários $(\mathrm{CS})$. Neste grupo de amostra $\mathrm{o}$ revendido ocorreu dentro do reator a plasma utilizando atmosfera inerte de $\mathrm{Ar}+\mathrm{H}_{2}$. O tratamento de revenimento foi realizado dois dias depois da têmpera e subzero. A microestrutura do grupo 6 é mostrada na Figura 4-f e assemelha-se aos grupos 1a 4. Os pontos pretos que aparecem nas imagens são efeitos de manchas de secagem e possíveis carbonetos removidos durante a preparação metalográfica das superfícies das amostras.

\subsubsection{Microscopia eletrônica de varredura(MEV).}

As imagens obtidas por MEV, da microestrutura do núcleo das amostras dos seis grupos, são mostradas na Figura 5. 

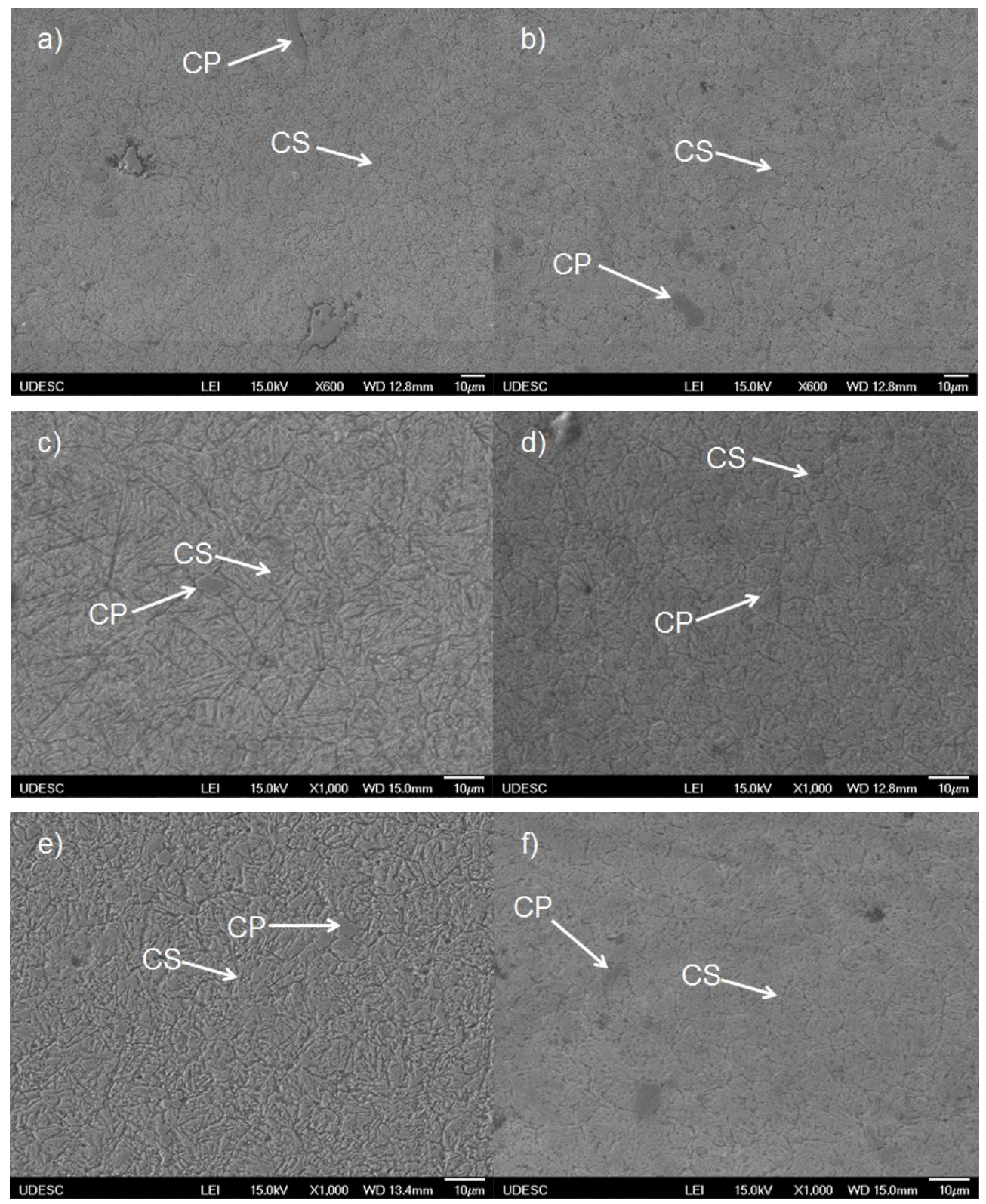

Figura 5: Micrografias da microestrutura do núcleo obtidas por MEV: (a) Grupo 1, (b) grupo 2, (c) grupo 3, (d) grupo 4, (e) grupo 5 e (f) grupo 6. Nital 10\%.

As imagens mostram a matriz martensita típica de aço VF 800 AT tratado termicamente e a presença de carbonetos primários (CP) e carbonetos secundários (CS). A microestrutura do grupo 5 (Figura 5-e) é composta por uma matriz martensítica, formada por ripas grosseiras. Embora a temperatura na superfície dessa amostra seja de $540{ }^{\circ} \mathrm{C}$ durante o revenimento a plasma, o seu núcleo estava em uma temperatura menor $\left(500{ }^{\circ} \mathrm{C}\right)$, devido ao gradiente térmico entre a superfície e o núcleo que é característico de processos a plasma. Esta diferença de temperatura de $40{ }^{\circ} \mathrm{C}$, como mostra a Figura 3 a e b, inibe a precipitação de carbonetos secundários que são responsáveis pelo endurecimento secundário. Segundo KRAUSS [8] o endurecimento secundário eficaz ocorre em temperaturas superiores a $520{ }^{\circ} \mathrm{C}$.

As Figuras 5-a, b e d, correspondentes aos grupos 1, 2 e 4 respectivamente, mostram microestruturas características de martensita revenida (ripas finas), com a presença de carbonetos primários com aspectos arredondados, carbonetos secundários solubilizados na matriz e contornos de grãos bem definidos sem a presença de austenita retida.

Os grupos 3 e 6 (Figuras 5-c e f) foram tratados termicamente com dois ciclos simultâneos de nitretação e revenimentos. $\mathrm{O}$ núcleo apresenta uma matriz martensítica revenida (menos refinada), carbonetos pri- 
mários e secundários. $\mathrm{O}$ efeito da matriz não estar refinada pode estar associado ao gradiente térmico entre o núcleo e a superfície do material, que durante o tratamento térmico foi de $35^{\circ} \mathrm{C}$.

\subsubsection{Perfil de microdureza no núcleo}

Um perfil de microdureza Vickers no núcleo das amostras é mostrado na Figura 6 para os seis diferentes grupos de amostras. Os grupos de 1 a 5 apresentam uma suave tendência de queda de microdureza a medida que se aproxima do centro da amostra. Para o grupo 6 em função da alta dispersão encontrada, não é possível afirmar qualquer tendência para este grupo. Os resultados mostram uma significativa diferença no perfil de microdureza entre a amostra do grupo 5 e os demais grupos. Isto é justificado porque o endurecimento secundário não ocorreu neste grupo, pois a temperatura do núcleo, durante o revenimento por plasma, foi de aproximadamente $500{ }^{\circ} \mathrm{C}$, inferior à temperatura eficaz para início do endurecimento secundário, que ocorre a partir de $520^{\circ} \mathrm{C}$ KRAUSS [8], DUDOVA, et al [9].O gradiente térmico entre a superfície e o núcleo das amostras é mostrada nos gráficos da Figura 3 a e b.

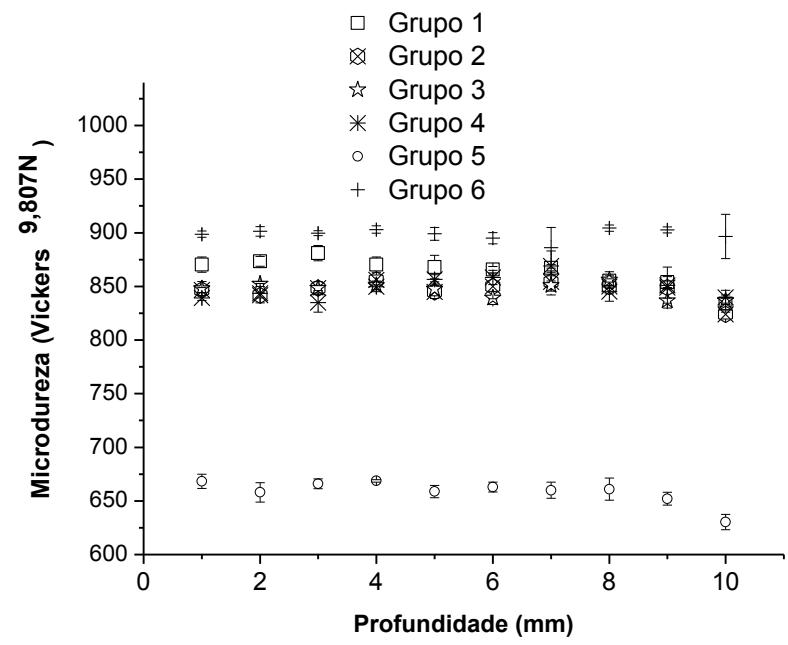

Figura 6: Microdureza Vickers em função da distância da superfície em relação ao núcleo da amostra.

Para a amostra do grupo 5 ocorreu um gradiente térmico de $40^{\circ} \mathrm{C}$ entre a superfície e o núcleo da amostra que estão separados por $12,70 \mathrm{~mm}$ de distância. Esta diferença de temperatura afeta as transformações na microestrutura, não efetivando a precipitação de carbonetos responsáveis pelo incremento de dureza pelo efeito de precipitação secundária de carbonetos. A variação de temperatura é fator importante a ser considerado em peças com dimensões grandes e prever seu efeito sobre as transformações metalúrgicas são importantes. Uma técnica para evitar a formação de gradiente térmico, entre a superfície e o núcleo da amostra, é usar uma fonte de aquecimento auxiliar. Por exemplo, usando câmara de parede quente, aquecidas por resistências elétricas PYE [10]. Dessa forma o plasma não seria a principal fonte de calor fornecido para a peça a ser tratada, possibilitando uma temperatura mais homogênea da mesma e, portanto, maior eficácia na simultaneidade do tratamento de revenimento e nitretação por plasma.

Para os grupos 1, 2, 3 e 4 a variação de dureza entre os grupos não é estatisticamente significativa. Sugere que o revenimento em altas temperaturas foi eficaz e permitiu que ocorresse aumento na dureza da matriz pelo incremento gerado com a precipitação de carbonetos secundários. Para o aço de trabalho a frio VF $800 \mathrm{AT}$ isto está associado a precipitação de carbonetos $\mathrm{Mo}_{2} \mathrm{C}$, que tem início em temperaturas acima de $520^{\circ} \mathrm{C}$,conforme CHI HONG-XIAO, et al [7].

\subsubsection{Caracterização do núcleo por difração de raios-X.}

A difração de raios- $\mathrm{X}$ do núcleo dos seis grupos é apresentada na Figura 7. Observam-se picos de difração que correspondem a fase $\alpha$ ' e carbonetos $\mathrm{M}_{7} \mathrm{C}_{3}$. A difração de raios $\mathrm{X}$ não consegue detectar frações de aus- 
tenita retida inferiores a 2\% (em volume), segundo SURBERG, et al[11]. Não observam-se picos da fase gama para nenhum dos seis grupos de amostras.

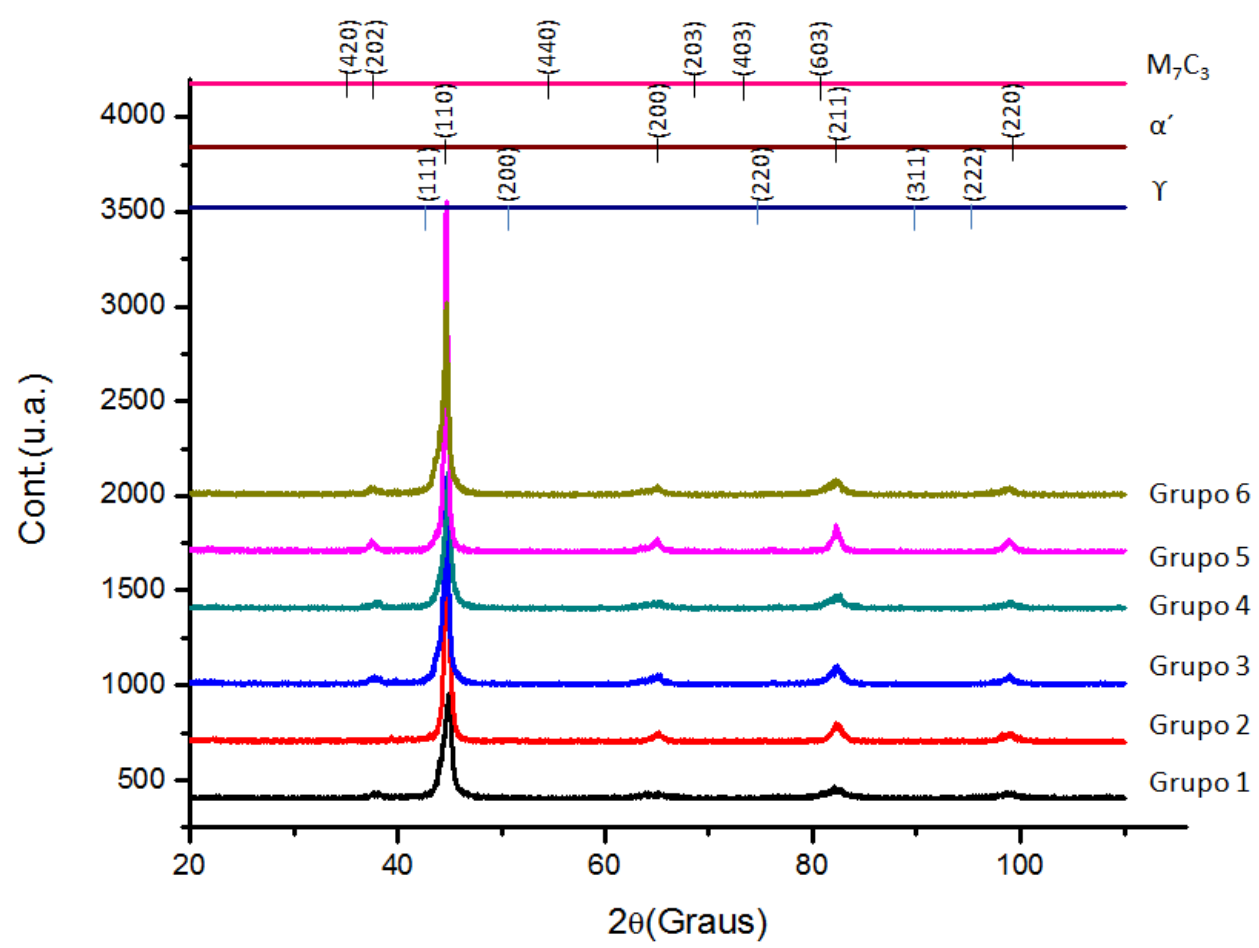

Figura 7: Análise de difração de raios-X dos seis grupos de amostras.

\subsubsection{Dureza Rockwell C do núcleo}

Os resultados de dureza Rockwell C (HRC) realizadas no centro geométrico das amostras dos seis grupos são mostrados na Figura 8.

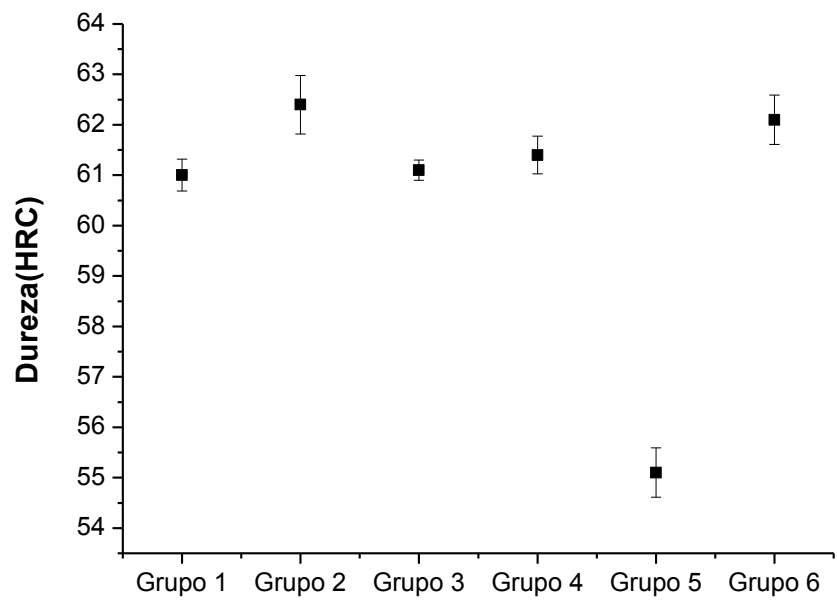

Figura 8: Dureza HRC do centro geométrico dos seis grupos de amostras.

Os resultados demonstram que os grupos 2 e 6 onde não foi aplicado alívio de tensões possuem maiores valores de dureza no centro da amostra. $\mathrm{O}$ alívio de tensões e o revenimento afetam a dureza do aço ferramenta conforme descrito por KOSKOSZA e PACYNA [12]: a cada ciclo de revenimento ocorrem trans- 
formações metalúrgicas, relaxamento de tensões residuais que afetam o valor de dureza do aço tratado termicamente.

Para os grupos 3 e 4, onde realizou-se o alívio de tensões e pelo menos um ciclo de revenimento em altas temperaturas (feito em forno Mufla), são observados valores de dureza semelhantes. Isso é um indicativo deque não ocorrem significativas alterações em relação ao ciclo convencional de alta tenacidade (Grupo2).

Para o grupo 5 é observado valores de dureza inferiores. Isto ocorre, pois não houve endurecimento secundário nessa amostra, devido ao fato da temperatura do centro do corpo de prova ser inferior a $520^{\circ} \mathrm{C}$ (Figura-3). Essa é a temperatura típica de início do efeito de endurecimento secundário que ocorre pela precipitação de carbonetos de Molibdênio $\mathrm{Mo}_{2} \mathrm{C}$ e Vanádio, conforme CHI HONG-XIAO, et al[7].

\subsection{Caracterizações da camada nitretada}

\subsubsection{Caracterização por microscopia óptica}

A análise metalográfica feita por microscopia óptica (Figura 9) revela a formação de camadas nitretadas sem a presença de camada branca, além de carbonetos primários e carbonetos secundários dispersos na matriz martensítica. A camada nitretada é composta de zona de difusão (região mais escura indicada pela seta preta) que comprova a efetiva nitretação da amostra para os respectivos grupos. O resultado é coerente com os resultados apresentados por FRANCO JR [2] e BOTH,[13] que mostram que, quando utilizamos percentagem de $5 \%$ de $\mathrm{N}_{2}$ no volume da atmosfera de tratamento, não ocorre a formação de camada branca para tempos de tratamentos inferiores a 10 horas.

A Figura 9 indica claramente que a espessura das camadas nitretadas foram superiores a $20 \mu \mathrm{m}$. Essas camadas são mais espessas que aquelas mencionadas na literatura, para aço D2, conforme ASM METALS HANBOOK[14]. Esse aumento na espessura é atribuído à adição de argônio na atmosfera de tratamento $\left(\mathrm{N}_{2} / \mathrm{H}_{2}+\mathrm{Ar}\right)$ por plasma. Com a adição de argônio se obtém camadas nitretadas mais espessas, com dureza superficial maior e sua presença retarda a formação de camada branca na superfície da amostra, devido à ativação da difusão de nitrogênio no sólido. Como os átomos de argônio possuem massa atômica próxima à dos átomos de ferro, há maior transferência de momento linear para a superfície do catodo (peça em tratamento) devido ao bombardeamento da superfície por íons $\mathrm{Ar}^{+}$. Dessa forma há maior aquecimento localizado da superfície além da formação de defeitos cristalinos na referida superfície da peça, que proporcionam incremento na difusão do nitrogênio (CONCI, et al [15]).

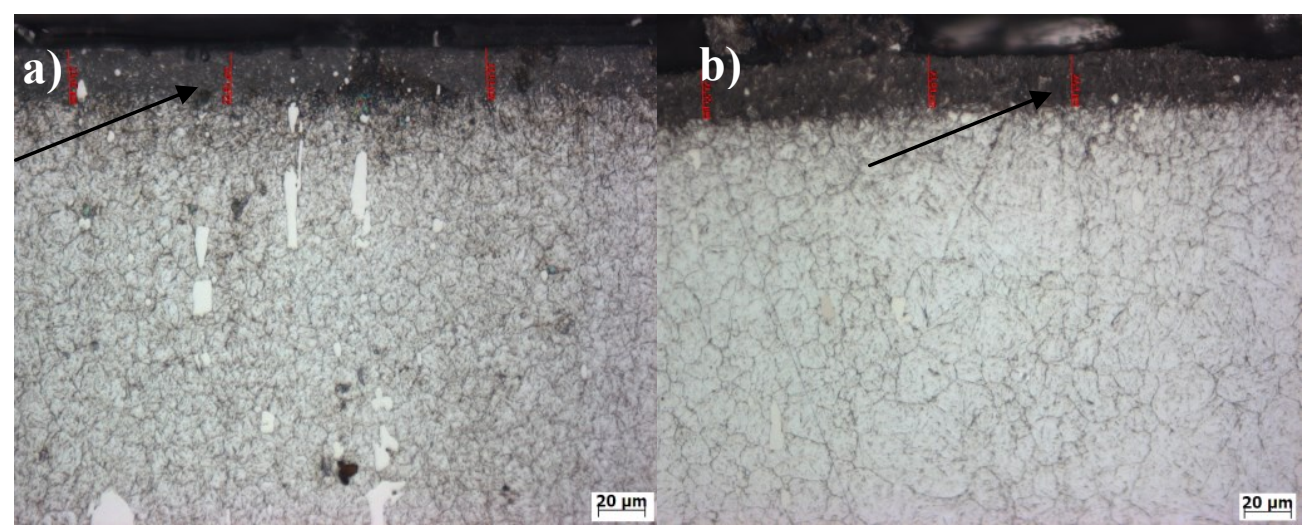




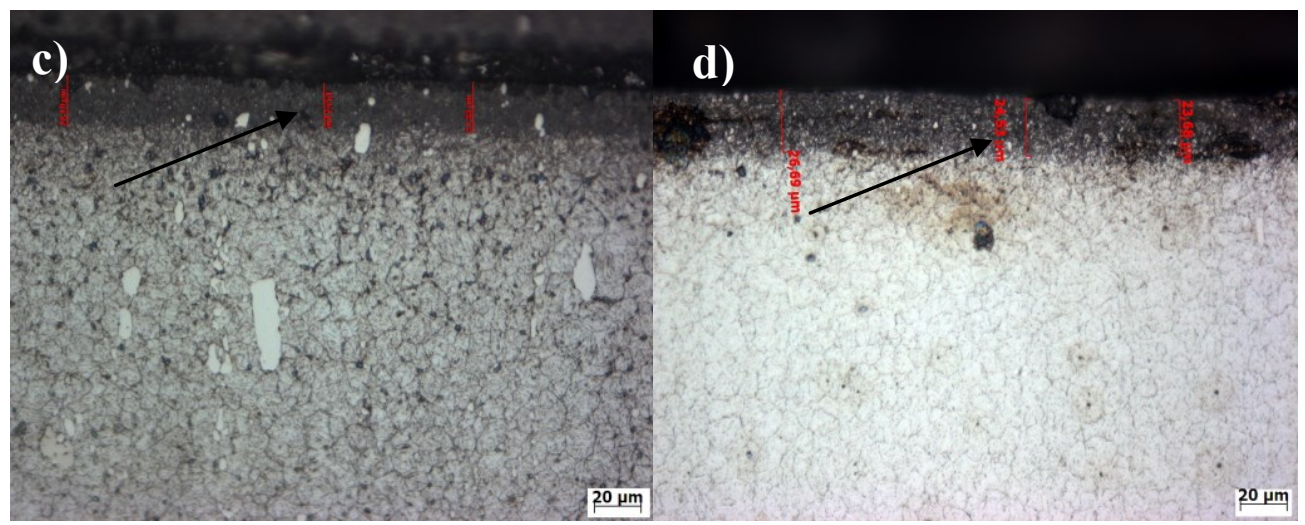

Figura 9: Microestrutura da camada nitretada: (a) grupo 1, (b) grupo 3, (c) grupo 4 e (d) grupo 6.

A camada branca (compostos $\mathrm{Fe}_{2-3} \mathrm{~N}$ e/ou $\mathrm{Fe}_{4} \mathrm{~N}$ ), que pode se formar durante a nitretação,tem elevada dureza, porém é uma camada frágil. Portanto, para muitas aplicações, como na nitretação de ferramentas de corte, é indesejável a formação dessa camada branca. Uma das técnicas para evitar a camada branca é pelo controle da atmosfera do plasma, daí o uso de argônio na composição do gás de trabalho. Além disso, a camada branca não é desejada nos aços ferramenta para trabalho a frio, pois, em caso da realização de tratamento duplex (nitretação e posterior deposição de filmes, por exemplo, TiN), os substratos com camada branca revestidos em temperaturas superiores às de nitretação possibilitam a decomposição da camada branca

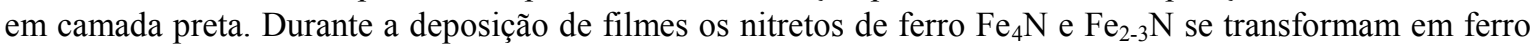
alfa, conforme SUN, et al [16]; sendo indesejada para a aplicação pois gera amolecimento do substrato podendo gerar colapso prematuro dos filmes finos. A nitretação do aço VF 800 AT, para ser usado como substrato em ferramentas de trabalho a frio, melhora a adesão entre o substrato e o filme, o que melhora o desempenho tribológico do conjunto.

As espessuras das camadas nitretadas estão mostradas na Figura 10. Os valores foram obtidos por diferentes técnicas, isto é: microscopia óptica, MEV e, indiretamente, pelo perfil de microdureza Vickers. Neste último método consideraram-se os critérios apresentados na norma DIN 50190 que determina critérios para avaliação da profundidade endurecida pela nitretação.

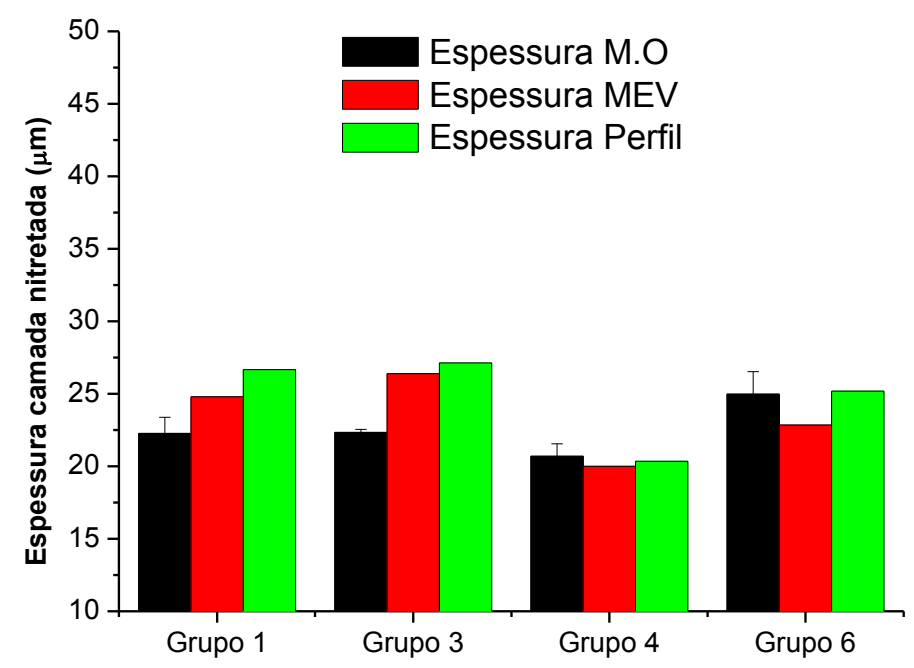

Figura 10: Espessuras das camadas nitretadas obtidas por diferentes métodos: microscopia óptica, MEV e pelo perfil de microdureza.

A espessura média da camada nitretada foi de $24 \pm 3 \mu \mathrm{m}$. As variações da espessura da camada nitretada estão associadas ao método utilizado na obtenção da medida e o acabamento superficial das amostras. 
Comparando os grupos 3 e 6, que foram durante 4 horas em dois ciclos de duas horas, com os grupos 1 e 4 , onde foi aplicado somente um ciclo de duas horas, constata-se que a espessura da camada nitretada é a mesma. Pela análise dos resultados constata-se que a cinética de formação das camadas nitretadas não é linear com o tempo. Nitretar durante 4 horas, em dois ciclos de 2 horas, possui um efeito diferente no crescimento da camada se comparado com um ciclo contínuo de nitretação durante 4 horas que não foi testado nesta pesquisa.

\subsubsection{Caracterização por microscopia eletrônica de varredura (MEV).}

As imagens da camada nitretada (MEV - Modo BSE, Figura 11) revelam a presença da camada de difusão [17], ausência da camada branca e precipitados nos contornos de grãos. Esses resultados são corroborados por dados obtidos da literatura, para tratamentos realizados em aço AISI D2 (o qual tem composição química similar ao VF800 AT), onde se constata a formação de camada nitretada isenta de camada branca para concentração de $\mathrm{N}_{2}$ de $5 \%$ no volume do gás de tratamento [2].
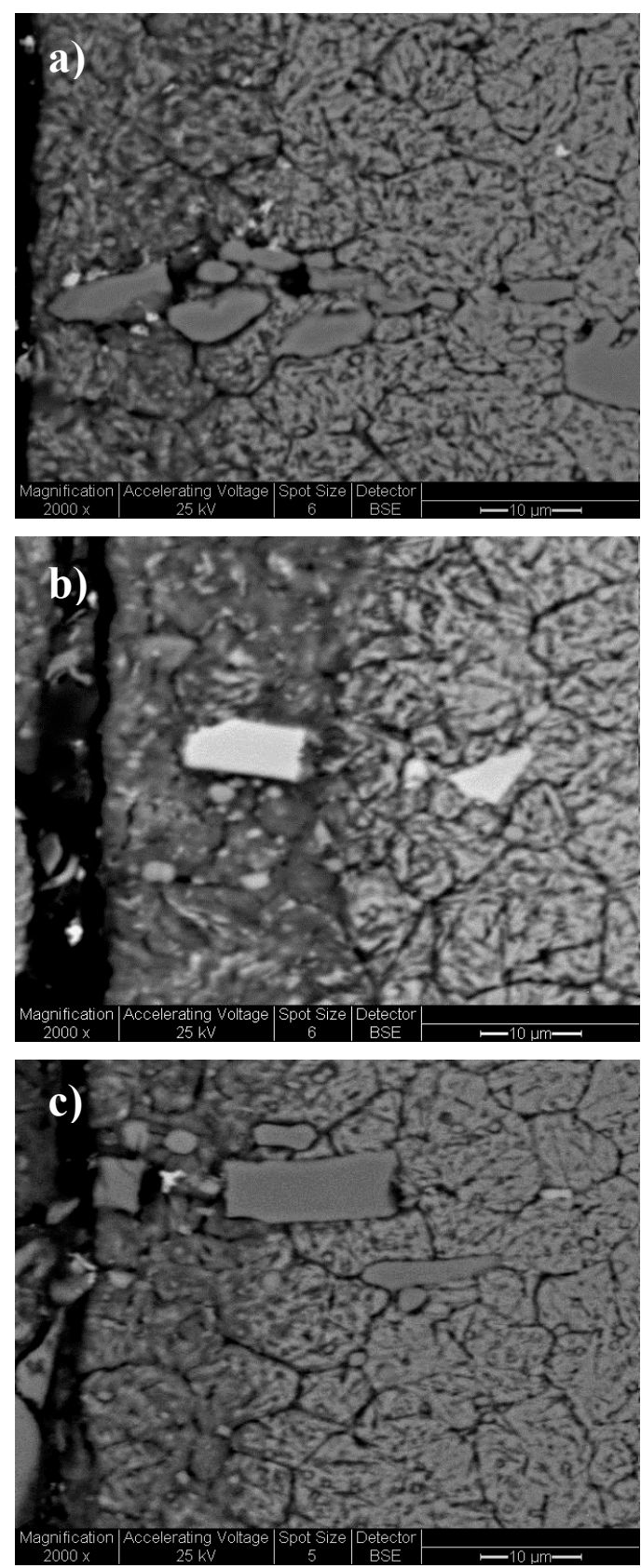


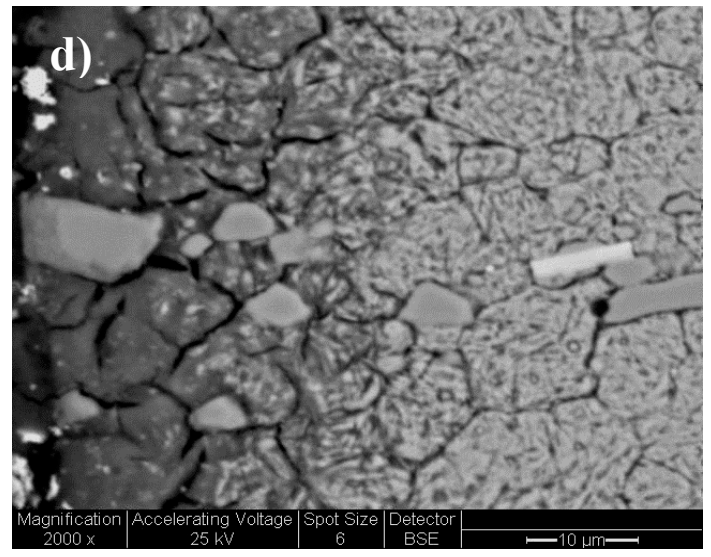

Figura 11: Microestrutura da camada nitretada obtida por MEV: (a) grupo 1, (b) grupo 3, (c) grupo 4 e (d) grupo 6.

\subsubsection{Perfil de microdureza}

Os perfis de microdureza Vickers (Figura 12) indicam que a camada formada pela nitretação a plasma provoca aumento de dureza superficial de até $40 \%$ em relação ao substrato do aço VF800 AT tratado termicamente. O endurecimento superficial do aço ferramenta reduz a deformação plástica e aumenta a resistência a abrasão. Além disso, uma microestrutura de camada nitretada (sem a presença de camada branca) pode induzir tensões residuais compressivas, que favorecem o aumento da resistência à fadiga de baixo ciclo e o aumento da capacidade de suportar carregamento do substrato (Load Bering capacity). Como já foi mencionado acima, a prénitretação do substrato melhora a adesão filme/substrato e, conseqüentemente, melhora o desempenho tribológico de ferramentas com tratamento duplex, conforme SUN, et al [18].

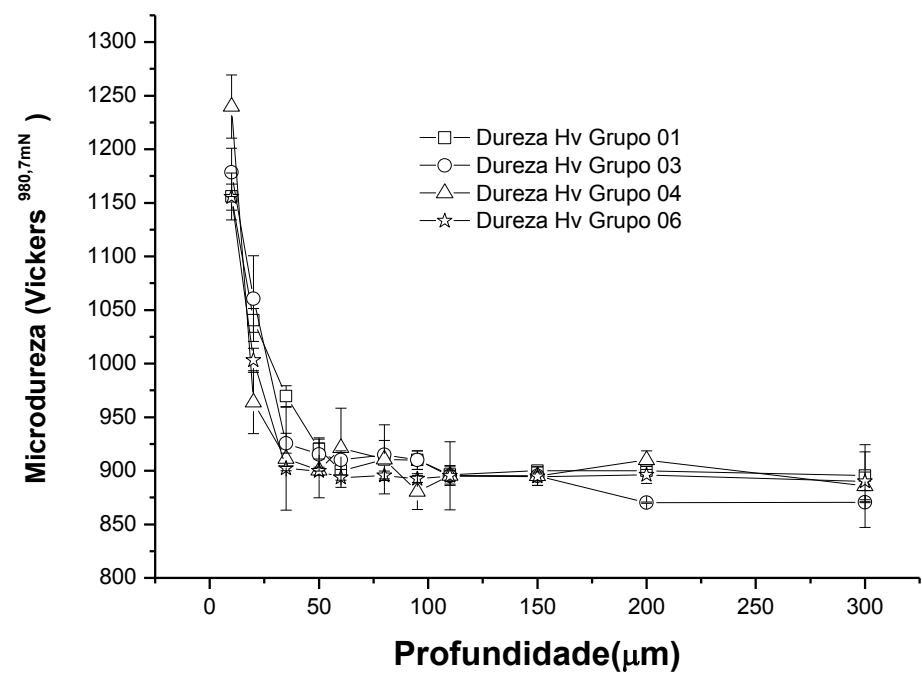

Figura 12: Perfil de microdureza da camada nitretada dos grupos 1, 3, 4 e 6.

\subsubsection{Caracterização das camadas nitretadas por difração de raios $\mathbf{x}$}

Os difratogramas de raios- $\mathrm{X}$ da superfície das amostras nitretadas são mostrados na Figura 13. Observam-se picos de difração da fase martensita, ausência de picos de nitretos de ferro ou de cromo e de austenita retida. Pelo uso desta técnica não é possível evidenciar a presença de quantidade significativa de austenita retida e nitretos (por exemplo, $\mathrm{Fe}_{4} \mathrm{~N}$ e $\mathrm{Fe}_{2-3} \mathrm{~N}$ ) na microestrutura da camada nitretada. É fato conhecido que níveis residuais de austenita retida em aços tratados termicamente sempre são encontrados, mas o limite de detecção desta técnica é de $2 \%$ no volume SURBERG, et al [11]. 


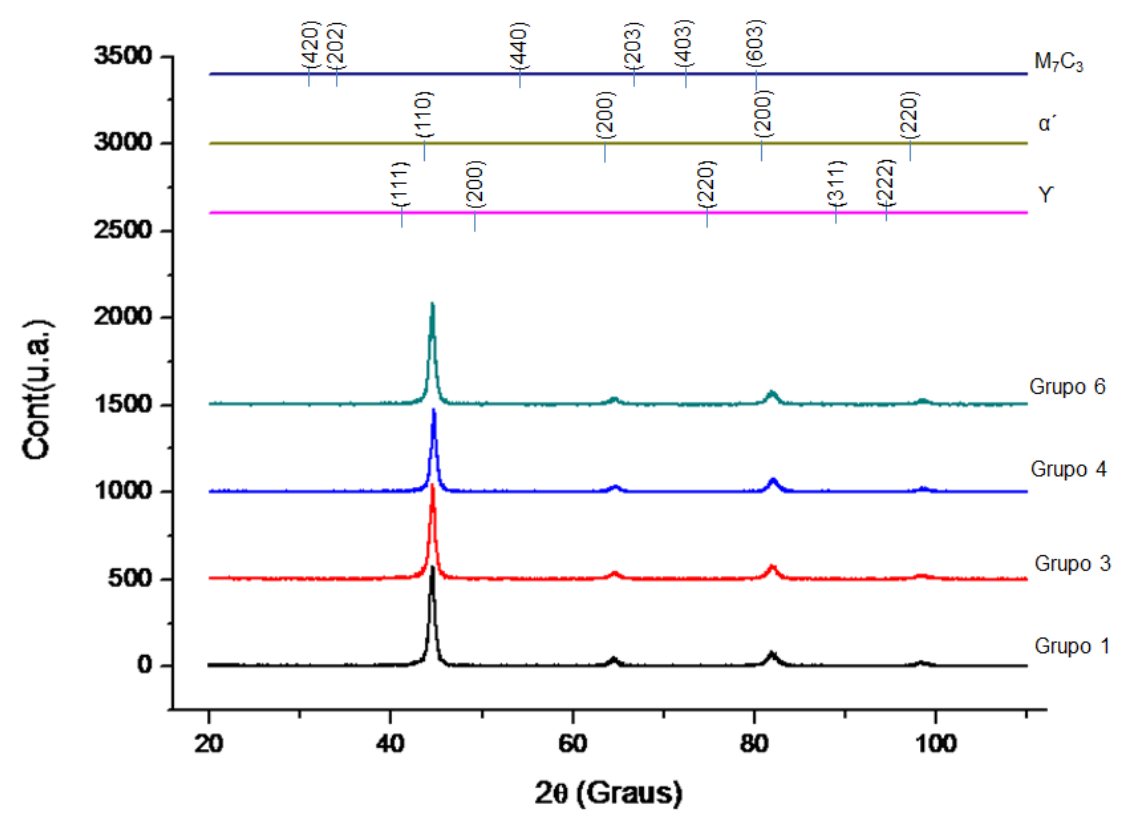

Figura 13: Análise de difração de raios-X da superfície nitretada: Grupos 1, 3, 4 e 6.

\section{CONCLUSÕES}

A nitretação a plasma e ou revenimento simultâneo com concentração de $5 \%$ de nitrogênio na mistura de gases de tratamento obteve apenas a zona de difusão (com espessura de $24 \mu \mathrm{m} \pm 3 \mu \mathrm{m}$ ) sem a presença de camada branca na região endurecida do aço ferramenta para trabalho a frio VF 800 AT. Isto permite a obtenção de um substrato para posterior aplicação de revestimentos de TiN, TiCN ou TiNAl(Tratamento duplex).

Os grupos 3, 4 e 6 que foram submetidas a pelo menos um ciclo de revenimento em alta temperatura; feito em forno Mufla; possuem valores dureza HRC estatisticamente iguais.

O gradiente térmico apresentado entre a superfície e o núcleo das amostras do aço ferramenta VF 800 AT tratado com ciclos simultâneos de revenimento e nitretação por plasma afeta a microestrutura e a dureza. Para minimizar estes efeitos, uma alternativa é realizar os ciclos em reatores por plasma com aquecimento auxiliar para reduzir a variação entre a temperatura do núcleo e a superfície das amostras.

Ocorre maior gradiente térmico entre a superfície e o núcleo da amostra, durante a nitretação por plasma em amostras que não sofreram tratamento de revenimento prévio em forno convencional (Mufla).

A aplicação de nitretação a plasma e revenimento em ciclo simultâneo reduz o tempo de tratamento térmico do aço ferramenta, reduz custo e tempo de fabricação e possibilita uso de novas tecnologias de equipamentos que estão sendo desenvolvidos.

\section{AGRADECIMENTOS}

Agradecimentos a EMBRACO, UDESC e TECNOTEMPERA por ceder suas estruturas para realização da pesquisa.

\section{BIBLIOGRAFIA}

[1] MENDANHA, A., FRANCO JR, A.R., GOLDENSTEIN, H., et al, Principais parâmetros metalúrgicos e sua influência na qualidade e desempenho do aço para trabalho a frio AISI D2 - Artigo de Revisão ABM, São Paulo, 2009.

[2] FRANCO JUNIOR, A.R. Obtenção de Revestimentos Duplex por Nitretação a Plasma e PVD-TiN em Aços Ferramenta AISI D2 e AISI H13, Tese de D. Sc., Escola Politécnica da Universidade de São Paulo, São Paulo, 2003.

[3] MEI, P. R., SILVA, A.L.C., Aços e ligas especiais. 3 ed.- São Paulo, Blucher,2010. 
[4] LESKOVSEK, V., PODGORNIK, B., Vacuum heat treatment, deep cryogenic treatment and simultaneous pulse plasma nitriding and tempering of P/M S390MC steel. Materials Science and Engineering A, v.531, pp.119-129, 2011.

[5] FARINA, P.F.S. Efeito das adições de tratamentos criogênicos e de alívio de tensões no ciclo térmico do aço AISI D2, Tese de D. SC., Escola Politécnica da Universidade de São Paulo, São Paulo, 2011.

[6] AKHBARIZADEH.A, et al., "Effects of Austenizing time on wear Behavior of D6 Tool Steel after Deep Cryogenic Treatment", Journal of iron and Steel research International, v.16, pp.29-32, 2009.

[7] CHI, HONG-XIAO., MA, DANG-SHEN., YONG, QI-LONG., et al., Effect of Cryogenic Treatment on Properties of Cr8-Type cold Work Die Steel, Journal of Iron and Steel Research, International, v.17, pp.4346,59, 2010.

[8] KRAUSS, G. Steels: Heat treatment and processing principles. 2ed., ASM International, Colorado, 1990.

[9] DUDOVA, N., KAIBYSHEV, R. "On the precipitation Sequence in a 10\% Cr Steel under Tempering", ISIJ Internationational, v.51, n.5, pp.826-831, 2011.

[10] PYE, D. Practical Nitriding and Ferritic Nitrocarburizing. ASM International, 2003.

[11] SURBERG, C.H., STRATTON, P., LINGENHÖLE, K. The effect of some heat treatment parameters on the dimensional stability of AISI D2, Criogenics, v. 48, pp.42-47, 2008.

[12] KOSKOSZA, A., PACYNA, J. "Evaluation of retained austenite stability in heat treated cold work tool steel”, JournalofMaterialsProcessing Technology, v.162-163, pp.327-331, 2005.

[13] BOTH, G.B, Características e avaliação tribológica de superfícies resistentes ao desgaste em aço ferramenta de conformação a frio, Dissertação de M. Sc, Universidade Federal do Rio Grande do Sul, Porto Alegre, 2011.

[14] ASM Metals Handbook - Metallografhy and microstruct, v. 9, ASM International, 1985.

[15] CONCI, M.D., BOZZI, A.C., FRANCO JUNIOR, A.R. "Effect of Plasma Nitriding Potential on Tribological Behaviour of AISI D2 cold Worked Tool Steel”, Wear,v.317, pp.188-193,2014.

[16] SUN, Y., BELL, T. "Plasma surface engineering of low alloy steel", Materials Science and Engineering $A$, v.140, pp.419-434, 1991.

[17] O'BRIEN, J.M., GOOFMAN, D., ASM Metals Handbook-Heat treatment, v.4, ASM International, 1991. [18] SUN, Y., BLOYCE, A., BELL, T. "Finite element analysis of plastic deformation of various TIN coating/substrate systems under normal contact with rigid sphere", Thin Solid Films, v. 271, pp.122-131, 1995. 